\title{
Rainfall Trends in Vietnam and Their Associations with Tropical Cyclones during 1979-2019
}

\author{
Ha Pham-Thanh ${ }^{1}$, Thanh Ngo-Duc ${ }^{2, *}$, Jun Matsumoto ${ }^{3,4}$, Tan Phan-Van ${ }^{1}$, and Hoa Vo-Van ${ }^{5}$ \\ ${ }^{1}$ Faculty of Hydrology, Meteorology and Oceanography, University of Science, \\ Vietnam National University, Hanoi, Vietnam \\ ${ }^{2}$ REMOSAT Laboratory, University of Science and Technology of Hanoi (USTH), \\ Vietnam Academy of Science and Technology (VAST), Hanoi, Vietnam \\ ${ }^{3}$ Department of Geography, Tokyo Metropolitan University, Tokyo, Japan \\ ${ }^{4}$ Dynamic Coupling of Ocean-Atmosphere-Land Research Program (D-COP), \\ Japan Agency for Marine Earth Science and Technology (JAMSTEC), Yokosuka, Japan \\ ${ }^{5}$ Northern Delta Regional Hydro-Meteorological Center, \\ Vietnam Meteorological and Hydrological Administration, Hanoi, Vietnam
}

\begin{abstract}
This study investigated rainfall trends and their associations with tropical cyclones (TCs) during the period of 1979-2019, using TC best-track data from the Regional Specialized Meteorological Center Tokyo - Typhoon Center and daily rainfall data from 138 meteorological stations in Vietnam. The radius of influence of TCs on local rainfall was limited to $500 \mathrm{~km}$ from TC centers. The average annual number of TCs affecting Vietnam has decreased slightly in the last two decades compared to previous decades. The ratio of $\mathrm{TC}$-induced rainfall to total rainfall attained the highest value of $37.3 \%$ in the central region, in July. The temporal distribution of TC-induced rainfall coincided with the frequency of TCs, with an active period from June to November. During 1979-2019, the non-TC rainfall was the main contributor to the change in total rainfall, especially in relation to the decline in the north and the increase in the coastal South Central region. The rainfall trend during the entire period was principally explained by the interdecadal shift in the late 1990s. Rainfall intensity and the number of heavy rainfall days were intensified for total rainfall and non-TC rainfall, indicating that TCs contributed minimally to the changes of extreme rainfall events during 1979-2019.

(Citation: Pham-Thanh, H., T. Ngo-Duc, J. Matsumoto, T. Phan-Van, and H. Vo-Van, 2020: Rainfall trends in Vietnam and their associations with tropical cyclones during 1979-2019. SOLA, 16, 169-174, doi:10.2151/sola.2020-029.)
\end{abstract}

\section{Introduction}

Changes in extreme weather and climatic events, including complex changes in rainfall, can have serious impacts on human life. Therefore, studying rainfall and mechanisms underlying its changes is very important and has been a concern of the global scientific community.

The IPCC (2007) concluded that downward trends in rainfall dominated tropical land areas since the 1970s. However, when more recent data were available, the IPCC (2013) stated that tropical terrestrial rainfall had increased over the last decade. Using data from 203 stations across Southeast Asia for the period 1950s-2000s, Endo et al. (2009) demonstrated that there were more stations with significant trends of declining rainfall, compared to those with significant trends of increasing rainfall. Total annual rainfall and several extreme rainfall indices increased in southern Vietnam, but decreased in northern Vietnam during the period 1950s-2007 (Endo et al. 2009), 1960-2011 (Ngo-Duc 2014), and 1961-2012 (Trinh-Tuan et al. 2019).

With its unique location on the east coast of the Indochina Peninsula, on the western North Pacific (WNP), Vietnam is frequently affected by tropical cyclones (TCs). The South China Sea (SCS) experienced a decrease, although not statistically significant, in the frequency of TCs during 1961-2010 for most best-track datasets (Lee et al. 2012). The annual number of SCS-generated TCs that landfall over Vietnam declined during 1949-2014 (Xiaoyan et al. 2017). Variations of TC activity affecting Vietnam were strongly associated with El Niño - Southern Oscillation (ENSO) events (Nguyen-Thi et al. 2012a).

A TC generally produces heavy rainfall and strong winds along its passage. Several previous studies provided estimations of TC-induced rainfall (hereinafter called TC rainfall) in the TC core region (e.g. Rao and MacArthur 1994; Rodgers et al. 2000; Nguyen-Thi et al. 2012a). The TC rainfall intensity of a region decreases when it is located far from the center of the TC (Rao and MacArthur 1994). Thus, TC rainfall could be defined by using distance from the center of the TC. Rodgers et al. (2000) used a distance of $444 \mathrm{~km}$ from the center of the TC and estimated that approximately $12 \%$ of the climatological rainfall over the WNP from June to November was due to TCs. Kubota and Wang (2009) chose a radius of $1000 \mathrm{~km}$ as the limit of influence of TCs. Nguyen-Thi et al. (2012a) used a distance of $600 \mathrm{~km}$ from the center of the TC and found that TC rainfall could contribute up to $25 \%$ of total rainfall in central Vietnam in September. However, the $600 \mathrm{~km}$ radius of influence was based on estimations from other regions of the world, and they did not examine the best distance specifically for Vietnam. In addition, data at only 15 stations located along the coast were used; therefore, no precise regional distribution on TC rainfall was presented.

Changes in TC activity can significantly affect TC rainfall. Lau and Zhou (2012) used a radius of $500 \mathrm{~km}$ and found that over the WNP, there was a reduction in TC rainfall by approximately $20.9 \% \pm 13.5 \%$ per decade for the period 1988-2007. Nguyen-Thi et al. (2012b) analyzed the trends of TC rainfall and TC heavy rainfall days for the period 1961-2008 over 58 stations in Vietnam. They found that both significantly increased for the central region but exhibited insignificant trends elsewhere.

The present study, using updated dense rainfall dataset from the meteorological station network of Vietnam aims to address questions pertaining to regional impacts of TCs on TC rainfall over Vietnam, and whether the changes of TC rainfall could partly explain the trends in rainfall in the last four decades.

Corresponding author: Thanh Ngo-Duc, REMOSAT Laboratory, University of Science and Technology of Hanoi (USTH), Vietnam Academy of Science and Technology (VAST), Hanoi, 100000, Vietnam. E-mail: ngoduc.thanh@usth.edu.vn.

(CThe Author(s) 2020. This is an open access article published by the Meteorological Society of Japan under a Creative Commons Attribution 4.0 International (CC BY 4.0) license (http://creativecommons.org/license/by/4.0). 


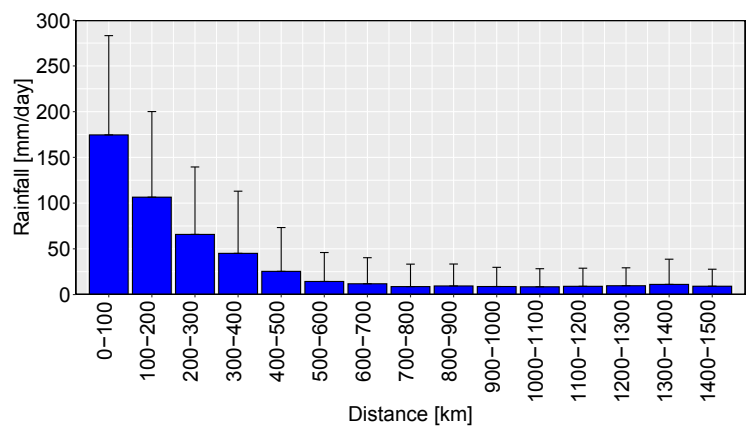

Fig. 1. Mean daily rainfall estimated from the 138 stations over Vietnam as a function of the distance between the center of a TC and a meteorological station for the period 1979-2019. The black bars indicate one standard deviation of individual stations from the mean.

\section{Data and study method}

\subsection{TC best-track and rainfall data}

Tropical cyclone best-track data from the Regional Specialized Meteorological Center (RSMC) Tokyo - Typhoon Center were used in this study. Song et al. (2010) demonstrated negligible differences in the tracks of different TC datasets since 1951 in the WNP. Thus, the choice of RMSC best-track data does not affect the analysis results for past TC tracks. Note that the RMSC provides TC best track data from the category of tropical storm (TS) when TC maximum wind speed exceeds $17.2 \mathrm{~m} \mathrm{~s}^{-1}$, which corresponds to force 8 winds of the Beaufort scale (Barua 2017).

Daily rainfall data observed at 172 meteorological stations of the Vietnam Meteorological Hydrological Administration (VMHA) were collected for the period of 1961-2019. As the number of stations with available data varied with time and significantly increased from 1976, and became relatively stable in 1979, the period 1979-2019 was chosen for examining changes of rainfall over Vietnam (Supplemental Fig. 1). Consequently, data from the same 138 stations of the total 172 stations covering this period were used.

\subsection{Rainfall indices, climate regime shifts, and trend estimation}

In addition to using total annual rainfall amount (PRCPTOT) and the number of wet days (WD, defined as the number of days when daily precipitation $\geq 1 \mathrm{~mm}$ ), two extreme rainfall indices were computed and analyzed, including 1) the simple precipitation intensity index (SDII), which is the annual rainfall divided by WD and 2) R50, defined as the number of days when daily precipitation $\geq 50 \mathrm{~mm}$. We also defined the TC rain-ratio as TC rainfall divided by total rainfall.

To detect shifts in climate regime during 1979-2019, the sequential t-test analysis proposed by Rodionov (2004) was applied with a cut-off length of 10 years and a significance level of 0.1 .

To investigate the long-term trend in rainfall, Sen's method (Sen 1968) was applied. The statistical significance level at $90 \%$ of the Sen's trend was obtained by using the nonparametric MannKendall test (Kendall 1975).

\section{Results}

\subsection{TC rainfall estimation}

Maximum average daily rainfall was approximately $175 \mathrm{~mm}$ within a radius of $100 \mathrm{~km}$ from the center of a TC (Fig. 1). Rainfall decreased with increased distance from the TC center. When the distance exceeded $500 \mathrm{~km}$, there was no further significant change of mean daily rainfall. The amount of rainfall within 500 $\mathrm{km}$ accounted for $80.6 \%$ of that within $1500 \mathrm{~km}$. Thus, we defined TC rainfall as the daily rainfall occurring when the center of the TC was within $500 \mathrm{~km}$ of the meteorological station. Non-TC (a) Monthly frequency of $500 \mathrm{~km}-\mathrm{TCs}$

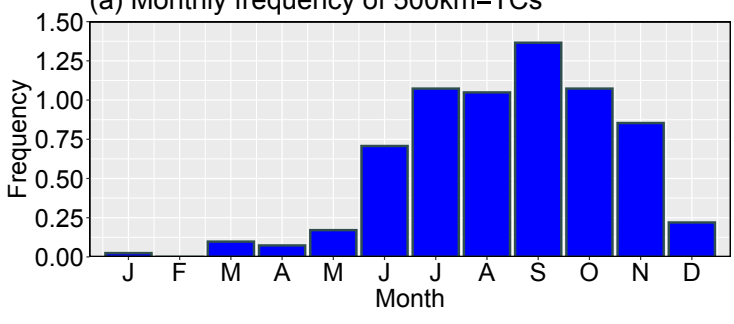

(b) Annual number of $500 \mathrm{~km}-\mathrm{TCs}$

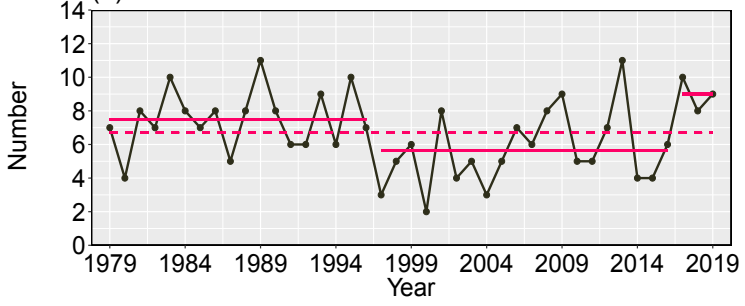

Fig. 2. (a) Monthly frequency; and (b) annual number of $500 \mathrm{~km}-\mathrm{TCs}$ affecting Vietnam during 1979-2019. Dashed and solid red lines in (b) indicate the mean values of the annual number of TCs for the entire period and for the different regimes detected by the Rodionov test (2004), respectively.

(NTC) rainfall was defined as the residual between total rainfall and TC rainfall. A TC having a center within $500 \mathrm{~km}$ of one of the 138 meteorological stations used in this study is hereinafter called a $500 \mathrm{~km}-\mathrm{TC}$. Our results reveal for the first time, the best distance for estimation of TC rainfall over Vietnam.

\subsection{General statistics of TC activities and TC rainfall}

The TCs affecting Vietnam often occurred from May to December, accounting for $97.1 \%$ of the total number of $500 \mathrm{~km}-$ TCs in the period 1979-2019 (Fig. 2a). September experienced the highest frequency of $500 \mathrm{~km}-\mathrm{TCs}$. The season of TCs affecting Vietnam coincided with the active TC season over the SCS (Wang et al. 2007).

During 1979-2019, there were, on average, 6.7 TCs per year occurring within $500-\mathrm{km}$ of any one of the stations used in this study (Fig. 2b). The largest annual number of $500 \mathrm{~km}-\mathrm{TCs}$ was 11, which occurred in 1989 and 2013. The smallest number was 2 , which occurred in 2000. A regime shift, from higher to lower $500 \mathrm{~km}-\mathrm{TC}$ numbers was identified in the late 1990s, and another shift from lower to higher $500 \mathrm{~km}-\mathrm{TC}$ numbers may have occurred in the late $2010 \mathrm{~s}$.

The annual average number of TCs occurring in the WNP has decreased in the last two decades compared to the two decades prior (1979-1998; Fig. 3). This trend is particularly significant in the central area of the SCS, which arose due to the northward migration of high TC frequency from this region in the late 1990s (Sun et al. 2019). The number of TCs affecting Vietnam also tended to slightly decrease in the period of 1999-2019 compared to that of 1979-1998. The decrease was statistically significant for a small area in the South Central and Central Highlands (Fig. 3c).

The average annual rainfall and TC rain-ratio in Vietnam are shown in Fig. 4. The annual rainfall across all Vietnam mostly ranged from $\sim 1400 \mathrm{~mm}$ to $\sim 2600 \mathrm{~mm}$, although some regions experienced annual rainfall exceeding $3500 \mathrm{~mm}$, including Bac Quang $\left(22.50^{\circ} \mathrm{N}, 104.87^{\circ} \mathrm{E}, 4621 \mathrm{~mm}\right)$, A Luoi $\left(16.22^{\circ} \mathrm{N}\right.$, 107.28 $\left.{ }^{\circ} \mathrm{E}, 3600 \mathrm{~mm}\right)$, Nam Dong $\left(16.17^{\circ} \mathrm{N}, 107.72^{\circ} \mathrm{E}, 3611 \mathrm{~mm}\right)$, Tra My $\left(15.33^{\circ} \mathrm{N}, 108.25^{\circ} \mathrm{E}, 4121 \mathrm{~mm}\right)$, Ba To $\left(14.77^{\circ} \mathrm{N}\right.$, $\left.108.73^{\circ} \mathrm{E}, 3622 \mathrm{~mm}\right)$. There are also some locations where total annual rainfall is significantly less than that in other regions, including the coastal region in South Central Vietnam. The average annual rainfall at Phan Rang station $\left(11.58^{\circ} \mathrm{N}, 108.98^{\circ} \mathrm{E}\right)$ is $808 \mathrm{~mm}$.

Along a north-south transect, TC rain-ratio was the highest in the central region from $12^{\circ} \mathrm{N}$ to $20^{\circ} \mathrm{N}$, especially at Da Nang 
(1979-1998)

(a)

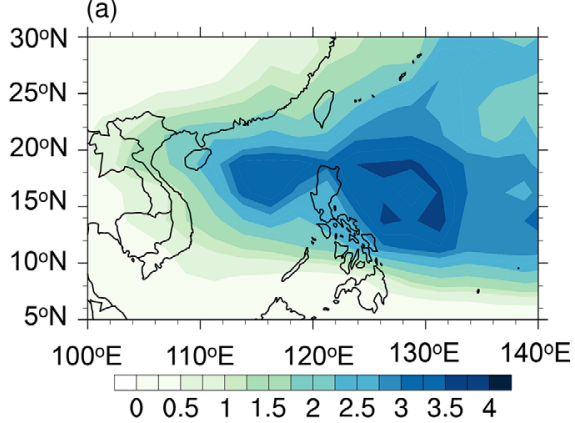

(1999-2019)

(b)

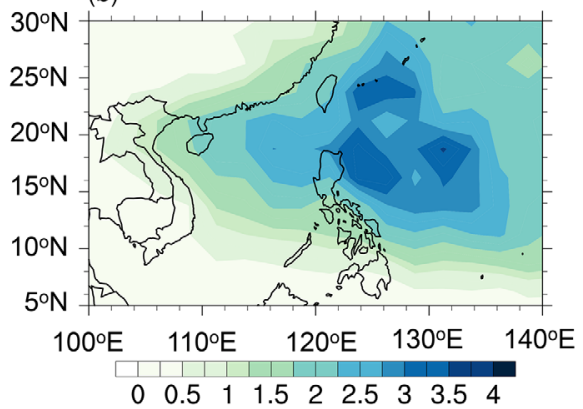

Difference (2019-1999) - (1998-1979)

(c)

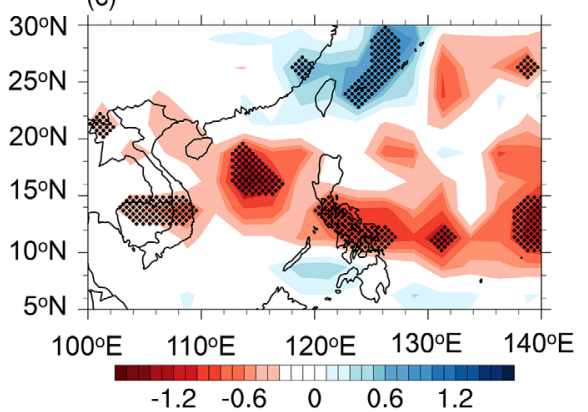

Fig. 3. Average annual frequency of TCs over the western North Pacific on each grid of $2.5^{\circ} \times 2.5^{\circ}$ during the periods a) $1979-1998$; b) $1999-2019$; and c) the difference between the later and previous periods. Dotted patterns in (c) indicate the statistically significant areas at the 0.1 level.
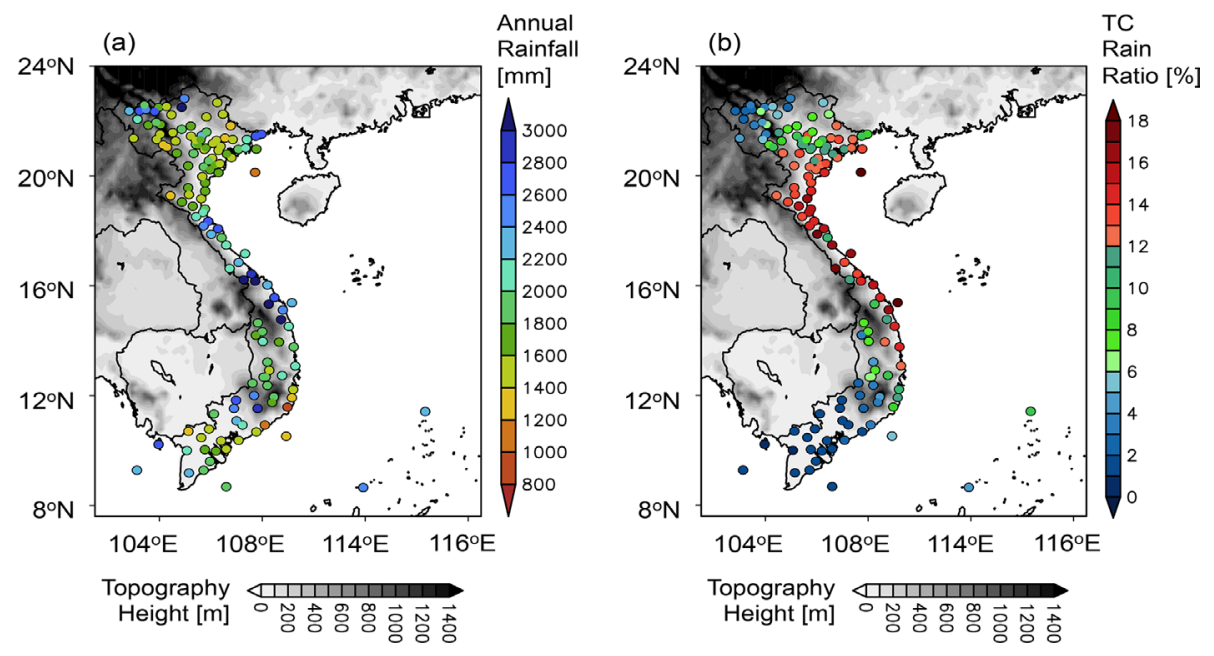

Fig. 4. (a) Climatological annual rainfall at the 138 stations used in this study; (b) average TC rain-ratio for the period 1979-2019.

$\left(16.03^{\circ} \mathrm{N}, 108.20^{\circ} \mathrm{E}\right)$, with an average annual $\mathrm{TC}$ rain-ratio of $19.8 \%$. The high TC rain-ratio in the central region can be explained by the larger number of TCs passing through this area per year. In contrast, at Bac Quang, which experiences a large annual rainfall, the ratio is $1.7 \%$. In general, stations with a high TC rain-ratio (from $\sim 10 \%$ to $\sim 20 \%$ ) are located near the coast. As the distance to the coast increases, TC rain-ratio generally decreases. TC rain-ratio is particularly small, generally less than $2 \%$ in Southern Vietnam, which is mainly due to the low frequency of TCs.

The distribution of monthly mean TC rain-ratio varies with latitude (Fig. 5). The TC rain-ratio exceeding $10 \%$ is mainly occurred between June and November, coinciding with the period of high TC frequency. Note that the number of $500 \mathrm{~km}$-TCs occurring from June to November accounted for $91.8 \%$ of the total number of TCs affecting Vietnam. The TC rain-ratio peaked at $37.3 \%$ and $34.6 \%$ in the North Central region in July and in the South Central region in November, respectively. From $11^{\circ} \mathrm{N}$ southward, the TC rain-ratio was small because of the low frequency of TCs over this region. Note that Nguyen-Thi et al. (2012a) also found a relatively high $\mathrm{TC}$ rain-ratio in the Central region of Vietnam, with a maximum of $\sim 25 \%$ in the region $16^{\circ} \mathrm{N}-18^{\circ} \mathrm{N}$, in September. The advantage of the present study is that more stations and more updated data (138 stations for the period 1979-2019 compared to 16 stations for the period 1961-2008 in Nguyen-Thi et al. 2012a) were used, thereby giving better spatial detail and more up-todate information. Figure 5 also shows a gradual shift over time, to the southern latitudes, of the TC rain-ratio maxima from July to November. The maximum TC rain-ratio in July was located in

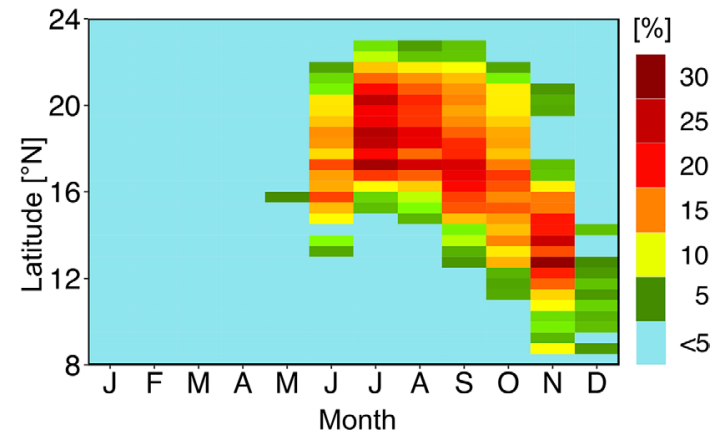

Fig. 5. Time-latitude distributions of monthly mean TC rain-ratio.

the North Central region while in November it was located in the South Central region. It is noteworthy that the TC season in the SCS was previously divided into early and late seasons (Goh and Chan 2010). In the early TC season, from May to September, most TCs occurred north of $12^{\circ} \mathrm{N}$ in the SCS, whereas in the late TC season, from October to December, the favorable regions for TC formation shifted to south of $18^{\circ} \mathrm{N}$ (Wang et al. 2007). Thus, the gradual shift over time of TC rain-ratio maxima can be explained by the seasonal southward shift of the dominant TC formation regions in the SCS. 


\section{PRCPTOT}

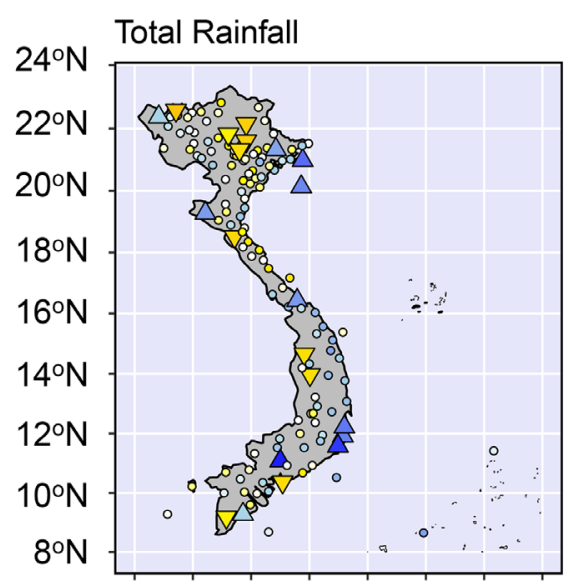

$102^{\circ} \mathrm{E} \quad 106^{\circ} \mathrm{E} \quad 110^{\circ} \mathrm{E} \quad 114^{\circ} \mathrm{E} \quad 102^{\circ} \mathrm{E} \quad 106^{\circ} \mathrm{E} \quad 110^{\circ} \mathrm{E} \quad 114^{\circ} \mathrm{E}$

\section{Difference (2019-1999)-(1998-1979)}

Total Rainfall

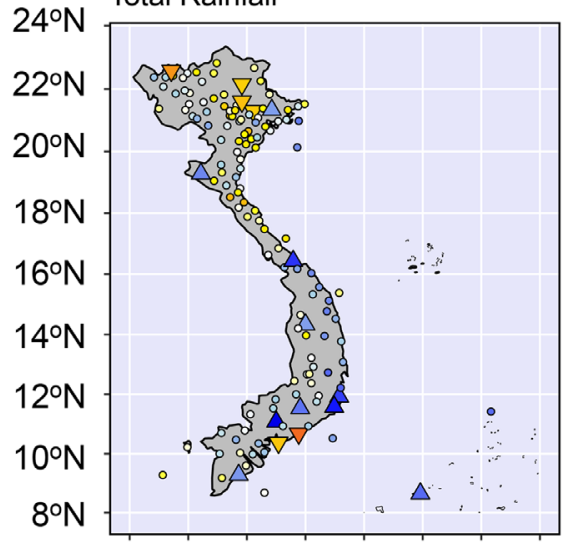

$102^{\circ} \mathrm{E} \quad 106^{\circ} \mathrm{E} \quad 110^{\circ} \mathrm{E} \quad 114^{\circ} \mathrm{E}$
TC Rainfall

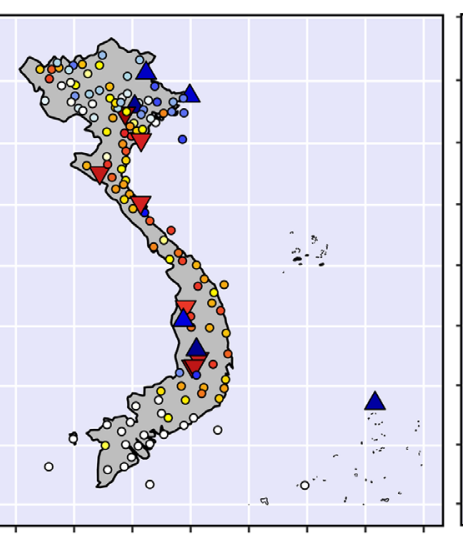

TC Rainfall

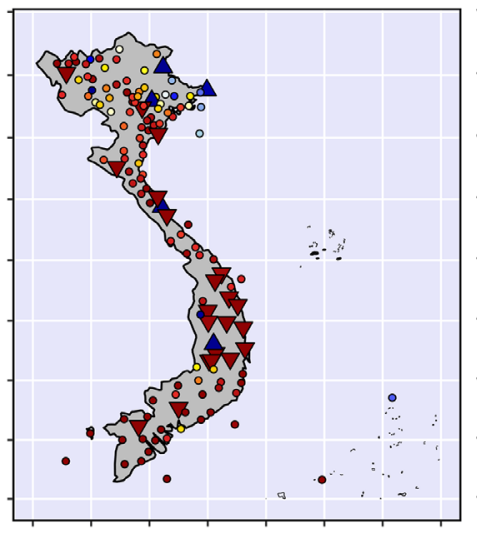

$102^{\circ} \mathrm{E} \quad 106^{\circ} \mathrm{E} \quad 110^{\circ} \mathrm{E} \quad 114^{\circ} \mathrm{E}$
NTC Rainfall

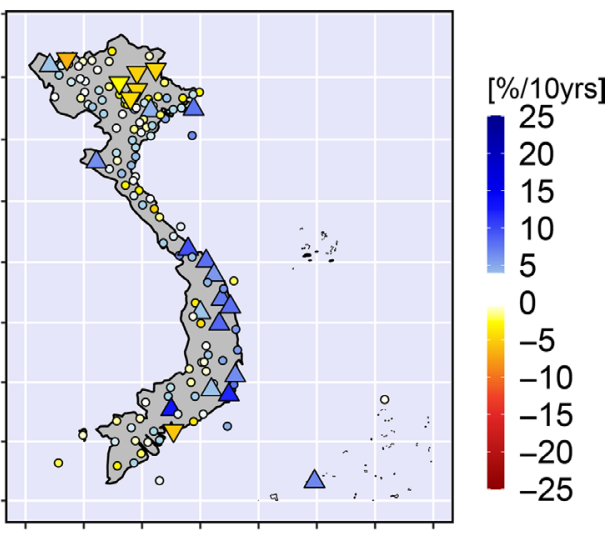

NTC Rainfall

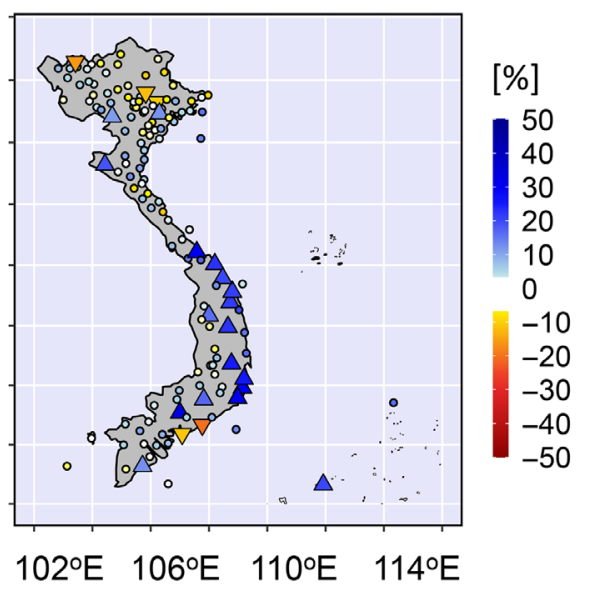

Fig. 6. Sen's trends over the period 1979-2019 (upper panel) and the differences between the period 1999-2019 and 1979-1998 for the total annual rainfall (left), TC rainfall (middle) and NTC rainfall (right) over the stations used in this study. Trends (differences) are expressed as the percentage per 10 years with respect to the mean value over the period 1979-2019. Circles denote non-significant trends (differences) while triangles denote statistical significance at the $5 \%$ level using the Mann-Kendall test (t-test).

\subsection{Trends during 1979-2019}

Total rainfall and NTC rainfall exhibited similar distribution of trends for the period 1979-2019, with a correlation of 0.91 over the 138 stations (Fig. 6). For both total rainfall and NTC rainfall, while more stations located north of $17^{\circ} \mathrm{N}$ exhibited slight declines, increases were more dominant south of $17^{\circ} \mathrm{N}$, particularly in the coastal South Central region. In contrast, TC rainfall exhibited upward trends in some stations located in the Central Highlands and the North of Vietnam. However, declines were more pronounced, particularly in the Central part of Vietnam. The lower panel of Fig. 6 displays the interdecadal differences, between 1999-2019 and 1979-1998, showing a high similarity with the Sen's trends over the entire period 1979-2019. This indicates that the trend of rainfall, particularly TC and NTC rainfall, during 1979-2019 can be mainly explained by the interdecadal shift in the late 1990s (see also Supplemental Fig. 2). The shifts of TC and NTC rainfall were clearly apparent, while no interdecadal shift was detected for total rainfall because the higher-to-lower shift of TC rainfall cancelled out the lower-to-higher shift of NTC rainfall in the late 1990s. The significant decrease of TC rainfall in the two most recent decades was associated with the decrease of $500 \mathrm{~km}-\mathrm{TC}$ frequency as shown in Fig. 3, thereby explaining the dominance of the decline in TC rainfall over the entire period
1979-2019. It can be concluded that the trends in annual total rainfall during 1979-2019, particularly the decline in the north and the increase in the coastal South Central region were mainly caused by the influence of NTC rainfall. Because the TC rain-ratio over the coastal South Central was rather important $(>10 \%$, Fig. 5), the trend of declines in TC rainfall, although insignificant, alleviated the significant trend of increasing NTC rainfall in the total signal. For other regions, the contribution of TC rainfall to total rainfall trends was minimal due to the relatively low TC rain-ratio.

The number of WD, calculated from total rainfall and NTC rainfall exhibited very similar trends at most stations, with significant declines at some stations in the North Delta, North Central and Central Highlands of Vietnam, and significant trends of increasing rainfall, mainly in the coastal areas of South Central and southern Vietnam (Fig. 7). The number of wet days caused by TCs decreased significantly in South Central and the Central Highlands of Vietnam while there were no clear trends in other regions.

The SDII reflects the results obtained with PRCPTOT and WD. There was a similar tendency for the SDII to increase over Vietnam for total and NTC rainfall. In some areas, including the Central Highlands, although no clear trends in PRCPTOT were apparent, the SDII still significantly increased due to the decrease of WD. R50 also exhibited similar behavior, indicating that 
WD

Total Rainfall

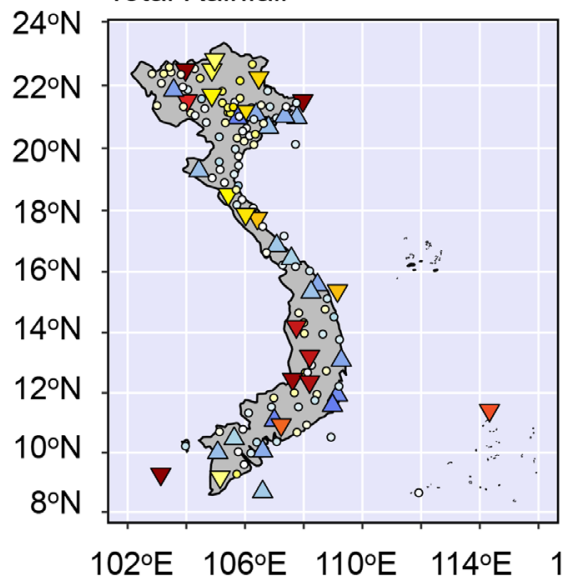

TC Rainfall

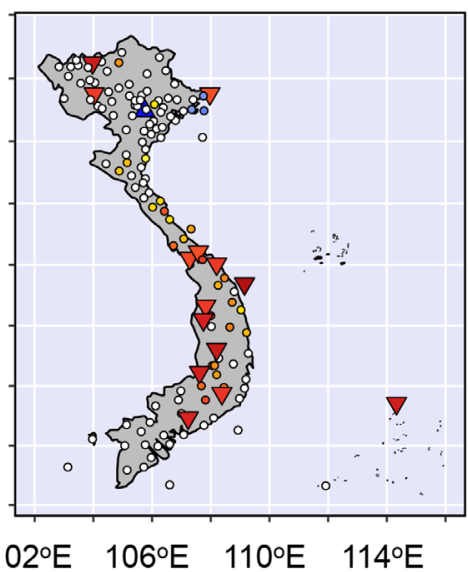

NTC Rainfall

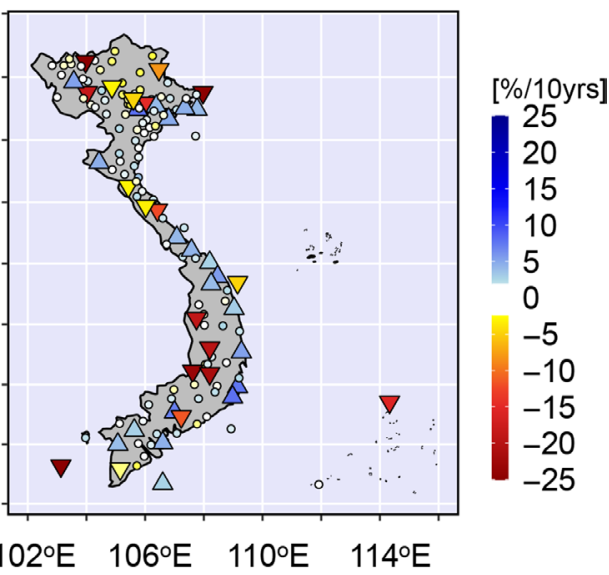

SDII

Total Rainfall

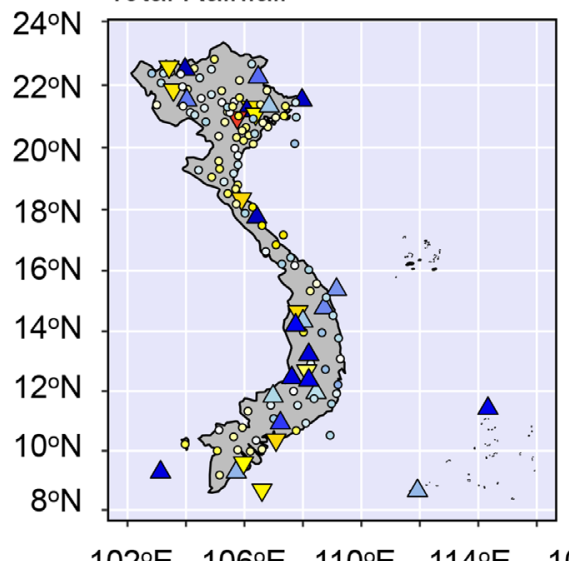

R50

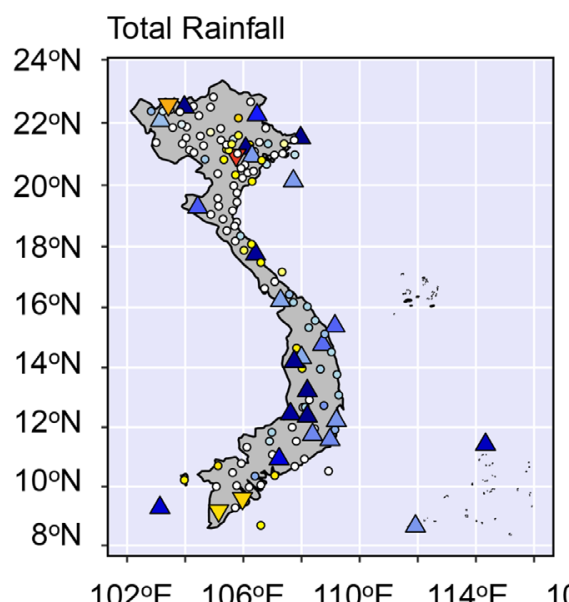

TC Rainfall

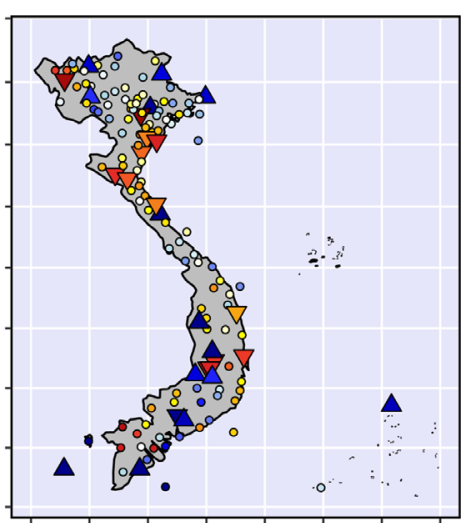

NTC Rainfall

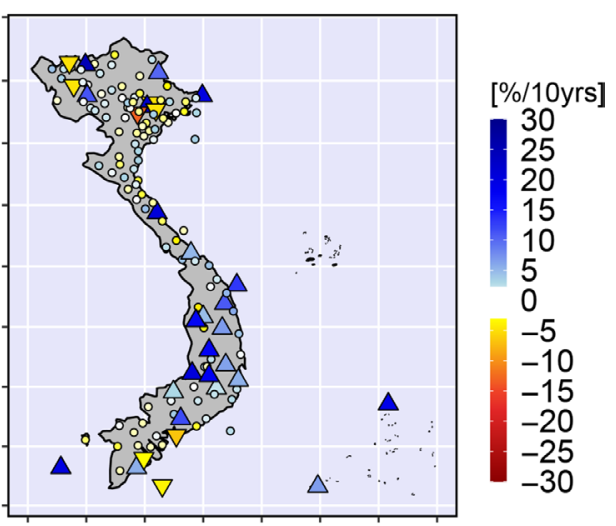

Fig. 7. As in upper panel in Fig. 6, but for WD (upper panel), SDII (middle panel), and R50 (lower panel).

although PRCPTOT can decrease over some areas, more extreme rainfall events can still occur. It is noteworthy that the SDII in the TC events decreased in North Central due to the decrease of TC rainfall and increased over some stations in the Central Highlands due to the decrease of WD. There were no clear trends for R50 in TCs.

\section{Conclusion}

This study demonstrated for the first time, the dependency of daily rainfall at 138 meteorological stations in Vietnam, on distance to the center of a TC. A radius of $500 \mathrm{~km}$ was identified 
as the sphere of influence for TCs during the period 1979-2019. The contribution of TC rainfall to annual total rainfall was more significant in coastal zones, which can account for 10 to $20 \%$ of the total annual rainfall in northern and central regions. The TC rain-ratio was particularly low (generally less than $2 \%$ ) in southern Vietnam due to the low frequency of TC over this region. In the Central region, the TC rain-ratio was relatively high between June and November and peaked at $37.3 \%$ in July.

The long-term trend analysis indicated that non-TC rainfall was the main contributor to the change in annual total rainfall during 1979-2019, especially for the decline in the north and the increase trend in coastal South Central regions. For other regions, the impact of TC rainfall on trends in total rainfall was minimal due to the relatively low TC rain-ratio. Moreover, the trends of total rainfall, TC rainfall and NTC rainfall during 1979-2019 were mainly explained by the interdecadal shift in the late $1990 \mathrm{~s}$. There was a general trend of increasing SDII of total rainfall and non-TC rainfall over Vietnam, which was also associated with the upward trend of R50. Furthermore, it is noteworthy that SDII in the TC events decreased in North Central regions and increased over some stations in the Central Highlands due to the decrease of TC rainfall and the decrease of WD, respectively. A detailed investigation of the mechanisms underpinning changes of non-TC rainfall is highly recommended to fully interpret previous trends of total rainfall over Vietnam.

\section{Acknowledgements}

We sincerely thank the editor and two anonymous reviewers for their helpful comments. This study is funded by the National Project code KC.09.15/16-20 (2017-2020) under the Ministry of Science and Technology of Vietnam. H. Vo-Van is supported by the Ministry of Natural Resources and Environment through the National Project code BDKH.25/16-20. T. Ngo-Duc is partly supported by Hanoi Forum (HNQT/QL/01.18). This study is also supported by the KAKENHI (19H00562) funded by the Japan Society for the Promotion of Science (JSPS), and the 2nd Earth Observation (EO) Project (PI No. ER2GPF008) of the Japan Aerospace Exploration Agency (JAXA).

Edited by: Y. Takaya

\section{Supplements}

Supplemental Fig. 1: The number of meteorological stations in Vietnam with available data for a given year within the period of 1961-2019. Green shading shows the period of 1979-2019 with continuous data from 138 stations (blue line) chosen for the analysis in this study.

Supplemental Fig. 2: Regime shifts of the total rainfall (upper panel), TC rainfall (middle panel) and NTC rainfall (lower panel) series detected by the Rodionov test (2004). Left and right columns indicate the values over the stations where average TC rain-ratios are greater and smaller than $15 \%$, respectively.

\section{References}

Barua, D. K., 2017: Beaufort Wind Scale. Encyclopedia of Coastal Science. Encyclopedia of Earth Sciences Series, Fink1, C., and C. Makowski C., Eds., Springer, Cham, doi:10.1007/ 978-3-319-48657-4.

Endo, N., J. Matsumoto, and T. Lwin, 2009: Trends in precipitation extremes over Southeast Asia. SOLA, 5, 168-171.

Goh, A. Z.-C., and J. C. L. Chan, 2010: Interannual and interdecadal variations of tropical cyclone activity in the South China Sea. Int. J. Climatol., 30, 827-843.

IPCC, 2007: Contribution of Working Group I to the Fourth Assessment Report of the Intergovernmental Panel on Climate
Change. Climate Change 2007: The Physical Science Basis, Solomon, S., D. Qin, M. Manning, Z. Chen, M. Marquis, K. B. Averyt, M. Tignor, and H. L. Miller, Eds., Cambridge University Press, Cambridge, United Kingdom and New York, NY, USA, 996 pp.

IPCC, 2013: Contribution of Working Group I to the Fifth Assessment Report of the Intergovernmental Panel on Climate Change. Climate Change 2013: The Physical Science Basis, Stocker, T. F., D. Qin, G.-K. Plattner, M. Tignor, S. K. Allen, J. Boschung, A. Nauels, Y. Xia, V. Bex, and P. M. Midgley, Eds., Cambridge University Press, Cambridge, United Kingdom and New York, NY, USA, 1535 pp.

Kendall, M. G., 1975: Rank Correlation Methods. Charles Griffin, London, $272 \mathrm{pp}$.

Kubota, H., and B. Wang, 2009: How much do tropical cyclones affect seasonal and interannual rainfall variability over the Western North Pacific? J. Climate, 22, 5495-5510.

Lau, W. K. M., and Y. P. Zhou, 2012: Observed recent trends in tropical cyclone rainfall over the North Atlantic and the North Pacific. J. Geophys. Res., 117, D03104.

Lee, T., C. Christy, Y. Y. Leung, M. H. Kok, and H. S. Chan, 2012: The long term variations of tropical cyclone activity in the South China Sea and the vicinity of Hong Kong. Tropical Cyclone Res. Rev., 1, 277-292.

Ngo-Duc, T., 2014: Climate change in the coastal regions of Vietnam. Coastal Disasters and Climate Change in Vietnam Engineering and Planning Perspectives, N. D. Thao, H. Takagi, and M. Esteban, Eds., Elsevier, Butterworth-Heinemann, ISBN: 978-0-12-800007-6, 175-198, doi:10.1016/ B978-0-12-800007-6.00008-3.

Nguyen-Thi, H. A., J. Matsumoto, T. Ngo-Duc, and N. Endo, 2012a: A climatological study of tropical cyclone rainfall in Vietnam. SOLA, 8, 41-44.

Nguyen-Thi, H. A., J. Matsumoto, T. Ngo-Duc, and N. Endo, 2012b: Long-term trends in tropical cyclone rainfall over Vietnam. J. Agrofor. Environ., 6, 89-92.

Rao, G. V., and P. D. Macarthur, 1994: The SSM/I estimated rainfall amounts of tropical cyclones and their potential in predicting the cyclone intensity changes. Mon. Wea. Rev., 122, 1568-1574.

Rodgers, E. B., R. F. Adler, and H. F. Pierce, 2000: Contribution of tropical cyclones to the North Pacific climatological rainfall as observed from satellites. J. Appl. Meteor., 39, $1658-1678$.

Rodionov, S. N., 2004: A sequential algorithm for testing climate regime shifts. Geophys. Res. Lett., 31, L09204.

Sen, P. K., 1968: Estimates of the regression coefficient based on Kendall's Tau. J. Am. Stat. Assoc., 63, 1379-1389.

Song, J.-J., Y. Wang, and L. Wu, 2010: Trend discrepancies among three best track data sets of western North Pacific tropical cyclones. J. Geophys. Res., 115, D12128.

Sun, J., D. Wang, X. Hu, Z. Ling, and L. Wang, 2019: Ongoing poleward migration of tropical cyclone occurrence over the western North Pacific Ocean. Geophys. Res. Lett., 46, 91109117.

Trinh-Tuan, L., R. T. Konduru, T. Inoue, T. Ngo-Duc, and J. Matsumoto, 2019: Autumn rainfall increasing trend in South Central Vietnam and its association with changes in Vietnam's East Sea surface temperature. Geographical reports of Tokyo Metropolitan University, 54, 11-22.

Wang, G., J. Su, Y. Ding, and D. Chen, 2007: Tropical cyclone genesis over the South China Sea. J. Mar. Syst., 68, 318326.

Xiaoyan, H., H. Li, Z. Huasheng, and H. Ying, 2017: Characteristics of tropical cyclones generated in South China Sea and their landfalls over China and Vietnam. Nat. Hazards, 88, 1043-1057.

Manuscript received 14 April 2020, accepted 29 July 2020

SOLA: https://www.jstage.jst.go.jp/browse/sola/ 